DOI: $10.5578 / \mathrm{fmbd} .66546$

\title{
Experimental and Theoretical Studies on Theobromine and Theobromine-Water Complexes
}

\author{
Mustafa Tuğfan BiLKAN \\ Department of Physics, Faculty of Science, Çankırı Karatekin University, 18100 Çankırı, Turkey \\ e-posta: mtbilkan@gmail.com
}

Keywords

Theobromine; Solvent effects; Hydrogen bonds; Vibrational spectroscopy; Density Functional Theory

\begin{abstract}
In this study, the solvent effects on structural, spectroscopic, electronic and thermochemical properties of Theobromine ( $\mathrm{tbH}$ ) were theoretically investigated. The dichloromethane (DCM), dimethylsulfoxide (DMSO) and water $\left(\mathrm{H}_{2} \mathrm{O}\right)$ solvents have been chosen for investigations. Optimized molecular structures of tbH were obtained by using the DFT/B3LYP method with $6-311++G(d, p)$ basis set in vacuum and in solvent media. Calculated geometric structure parameters were compared with experimental data. In the experimental section, the mid-IR spectrum of $\mathrm{tbH}$ was recorded using ATR equipment and compared with calculated vibrational frequencies. $\mathrm{tbH}-\mathrm{H}_{2} \mathrm{O}$ complexes were studied for various binding ratios. The total energies and hydrogen bond lengths of these complexes were discussed in detail. It is seen as the result of this study that $\mathrm{N} \cdots \mathrm{H}-\mathrm{O}$ and $\mathrm{O} \cdots \mathrm{H}-\mathrm{O}$ non-covalent bonded structures are more stable for all binding versions and hydrogen bond lengths for all tbH- $\mathrm{H}_{2} \mathrm{O}$ complexes range from 1.8-2.5 Å.
\end{abstract}

\section{Teobromin ve Teobromin-Su Bileşikleri Üzerine Deneysel ve Teorik Çalışmalar}

\author{
Anahtar kelimeler \\ Teobromin; Çözücü \\ etkileri; Hidrojen \\ bağları; Titreşim \\ spektroskopisi; \\ Yoğunluk Fonksiyonel \\ Teorisi
}

\begin{abstract}
Özet
Bu çalışmada Teobromin'in (tbH) yapısal, spektroskopik, elektronik ve termokimyasal özellikleri üzerine çözücü etkileri teorik olarak incelenmiştir. İncelemelerde, diklorometan (DCM), dimetilsülfoksit (DMSO) ve su $\left(\mathrm{H}_{2} \mathrm{O}\right)$ çözücüleri seçilmiştir. tbH'nin optimize edilmiş moleküler yapıları, DFT/B3LYP metodu ve 6$311++G(d, p)$ temel seti kullanılarak vakum ve çözücü ortamlarda elde edilmiştir. Çalışmanın deneysel kısmında, tbH orta-bölge IR spektrumu, ATR sistemi ile kaydedilmiş ve deneysel sonuçlar hesaplanan verilerle kıyaslanmıştır. Farklı bağlanma oranları için, $\mathrm{tbH}-\mathrm{H}_{2} \mathrm{O}$ bileşikleri çalışılmıştır. Bileşiklerin toplam enerjileri ve hidrojen bağ uzunlukları detaylı bir şekilde incelenmiştir. Yapılan bu çalışmanın

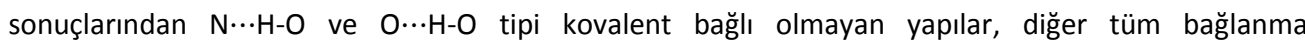
durumlarından daha kararlıdır ve bileşiklerin hidrojen bağ uzunlukları 1.8-2.5 Å aralığında değişmektedir
\end{abstract}

(c) Afyon Kocatepe Üniversitesi

\section{Introduction}

Ligand-water interaction is an important issue in the search for bio-molecular activities because most living organisms contain water and all biological processes occur in the aquatic environment in living cells. Generally, such interactions occur in the form of hydrogen-bonded compounds. In these compounds, a water molecule is often bound to the ligand molecules or other water molecule by a hydrogen bond. For example, nucleobases interact via hydrogen bonds (Fornaro et al. 2015). Due to its importance, there are many published studies in the literature in this topic (Parthasarathi et al. 2005, Calabrese et al. 2016, Kwak et al. 2008, Bernar et al. 2009). In calculating physical and chemical properties of any molecular system, hydrogenbonded interactions are important, but they have some burdensome aspects. Although the determination of a potential energy surface for biomolecule-water complex systems, using ab initio techniques, is extremely difficult, these techniques 
can provide valuable insight into the details of the interaction (Mourik et al. 1999). Also, ab initio techniques can provides important facilities to study of the physical and chemical properties of complex systems with inter and intramolecular interactions. In this paper, solvent effects on spectroscopic and structural properties of theobromine $(\mathrm{tbH})$ were studied in detail. tbH is an important alkaloid. It has been investigated by scientists for many years because of its commercial and scientific importance (Cook and Regnier 1967, Mikulski et al. 2007, Ford et al. 1998). It is also known with biological and pharmacological activities in living organisms (Oettle and Reibnegger 1999, Tewari et al. 2012). To the best of our knowledge, there are not enough studies in the literature on the investigation of solvent effects on tbH. Recently, we published a solvent effect study on tbH (Bilkan 2017). In the past, Ucun et al. have done some quantum chemical calculations on molecular structures and vibrational frequencies of various xanthine derivatives by Hartree-Fock and Density Functional Theories (Ucun et al. 2007). In this study, for the investigation of solvent effects on $\mathrm{tbH}$, basically two strategies were used, including implicit and explicit. The solvent effects were investigated in different solvent media (polar protic, polar aprotic and nonpolar) using the Polarizable Continuum Model (PCM) (Miertus et al. 1981). Subsequently, the tbH- $\mathrm{H}_{2} \mathrm{O}$ complexes were examined for different binding ratios. The solidphase experimental FT-IR spectrum of tbH was recorded and compared with the calculated vibrational data. Moreover, some important electronic properties such as the electrophilicity $(\omega)$, global hardness $(\eta)$, chemical potential $(\mu)$, ionization potential (I) and electron affinity (A) (Wang et al. 2015) were calculated to identify the nature of pharmacological properties of $\mathrm{tbH}$.

\section{Materials and Methods}

\subsection{Computational methods}

The energies, thermochemical properties, optimized molecular structures, vibrational frequencies and electronic properties of $\mathrm{tbH}$ were calculated using the Gaussian03 program and the Gaussview visualization program (Frisch et al. 2003,
Denington et al. 2008). The calculated frequencies were scaled by 0.9668 (Yurdakul and Bilkan 2015) to correct for the difference between the calculated and the experimental vibrational frequencies. Firstly, the optimized molecular structures of tbH in vacuum and solvent media were performed using by $6-311++G(d, p)$ basis set. Secondly, based on the optimized structures, some of physical and chemical properties were calculated. The fundamental vibrational modes were characterized by their PED (potential energy distribution) obtained by using the VEDA4 program (Jamróz 2004).

\subsection{Experimental procedures}

In the experimental section of this study, tbH was purchased from Sigma-Aldrich and used without further purification. The infrared spectrum of tbH was recorded between $3700-550 \mathrm{~cm}^{-1}$ by PerkinElmer 100 spectrum FT-IR spectrometer with Attenuated total reflection (ATR) equipment in Çankırı Karatekin University Central Research Laboratory.

\section{Results and Discussions}

\subsection{Molecular structure and geometry optimization}

The optimized molecular structure of tbH is present in Figure 1. The bond lengths and bond angles of optimized structures are given in Table 1. The selected experimental values of molecular parameters were taken from the literature 9 and compared with the calculated ones in Table 1.

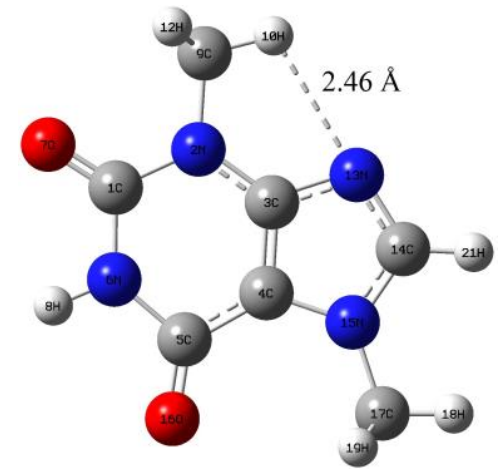

Figure 1. Optimized molecular structure of isolated tbH

Solvent effects on the geometry of tbH were investigated using three different solvents. As can be seen from Table 1, in most cases, calculated bond 
lengths are in good agreement with the experimental data. The calculated bond lengths have minor deviations compared to the experimental ones. Moreover, there are minor variations in bond length values calculated in different solvent environments.

Table 1. Optimized geometric parameters of tbH in different solvent media.

\begin{tabular}{|c|c|c|c|c|c|}
\hline \multirow{2}{*}{ Lengths } & \multirow{2}{*}{ Vacuum } & \multirow{2}{*}{$\frac{\text { Non-polar }}{\text { DCM }}$} & \multicolumn{2}{|c|}{ Polar } & \multirow{2}{*}{ Exp.* } \\
\hline & & & DMSO & $\mathrm{H}_{2} \mathrm{O}$ & \\
\hline $1 C-2 N$ & 1.393 & 1.386 & 1.385 & 1.385 & 1.377 \\
\hline $1 C-70$ & 1.215 & 1.222 & 1.223 & 1.223 & 1.231 \\
\hline $3 C-4 C$ & 1.383 & 1.385 & 1.386 & 1.386 & 1.364 \\
\hline $3 C-13 N$ & 1.371 & 1.370 & 1.370 & 1.370 & 1.363 \\
\hline $4 C-5 C$ & 1.434 & 1.430 & 1.429 & 1.429 & 1.426 \\
\hline $4 \mathrm{C}-15 \mathrm{~N}$ & 1.403 & 1.403 & 1.403 & 1.403 & 1.388 \\
\hline $5 C-6 \mathrm{~N}$ & 1.411 & 1.407 & 1.407 & 1.407 & 1.397 \\
\hline $5 C-160$ & 1.220 & 1.225 & 1.226 & 1.226 & 1.225 \\
\hline $6 \mathrm{~N}-8 \mathrm{H}$ & 1.012 & 1.013 & 1.013 & 1.013 & 0.856 \\
\hline $14 C-15 N$ & 1.343 & 1.339 & 1.339 & 1.339 & 1.343 \\
\hline $14 C-13 N$ & 1.292 & 1.296 & 1.296 & 1.296 & 1.339 \\
\hline $2 N-9 C$ & 1.465 & 1.467 & 1.467 & 1.467 & 1.473 \\
\hline $9 \mathrm{C}-10 \mathrm{H}$ & 1.087 & 1.086 & 1.086 & 1.086 & 1.039 \\
\hline $9 \mathrm{C}-12 \mathrm{H}$ & 1.092 & 1.090 & 1.090 & 1.090 & 0.971 \\
\hline $17 \mathrm{C}-20 \mathrm{H}$ & 1.090 & 1.089 & 1.089 & 1.089 & 1.034 \\
\hline \multicolumn{6}{|l|}{ Angles } \\
\hline $2 N-1 C-6 N$ & 115.34 & 115.74 & 115.79 & 115.79 & 116.37 \\
\hline $2 \mathrm{~N}-1 \mathrm{C}-7 \mathrm{O}$ & 122.68 & 122.57 & 122.57 & 122.57 & 122.10 \\
\hline $6 N-1 C-70$ & 121.99 & 121.70 & 121.64 & 121.64 & 121.53 \\
\hline $4 C-3 C-13 N$ & 110.77 & 110.80 & 110.80 & 110.80 & 112.72 \\
\hline $4 C-3 C-2 N$ & 122.86 & 122.89 & 122.89 & 122.89 & 122.40 \\
\hline $3 C-4 C-5 C$ & 122.84 & 122.44 & 122.39 & 122.39 & 122.94 \\
\hline $4 C-5 C-160$ & 128.58 & 128.71 & 128.74 & 128.74 & 128.63 \\
\hline $15 N-14 C-13 N$ & 116.50 & 116.75 & 116.78 & 116.78 & 114.30 \\
\hline $4 C-15 N-14 C$ & 103.93 & 103.88 & 103.87 & 103.87 & 105.62 \\
\hline $1 \mathrm{C}-2 \mathrm{~N}-3 \mathrm{C}$ & 119.23 & 119.11 & 119.09 & 119.09 & 118.91 \\
\hline $3 C-2 N-9 C$ & 122.04 & 122.12 & 122.11 & 122.11 & 121.76 \\
\hline $1 C-6 N-5 C$ & 130.05 & 129.77 & 129.72 & 129.72 & 129.10 \\
\hline $1 \mathrm{C}-6 \mathrm{~N}-8 \mathrm{H}$ & 114.16 & 114.40 & 114.43 & 114.43 & 116.67 \\
\hline
\end{tabular}

The calculated $\mathrm{C}-\mathrm{C}$ and $\mathrm{C}-\mathrm{N}$ bond lengths are very close to the experimental values. Deviations between calculated and experimental values are less than $0.02 \AA$. Importantly, since the bond between atoms $3 \mathrm{C}-4 \mathrm{C}$ is a double bond, the bond length of $3 \mathrm{C}-4 \mathrm{C}$ atoms is shorter than the bond length of $4 \mathrm{C}-5 \mathrm{C}$ atoms. Compatibility with the experiment was also observed in the calculation of $\mathrm{C}-\mathrm{O}$ bond lengths. Both $1 \mathrm{C}-7 \mathrm{O}$ and $5 \mathrm{C}-16 \mathrm{O}$ bond lengths were calculated in accordance with the experimental data. When Table 1 is analyzed, it is evident that the $6 \mathrm{~N}-8 \mathrm{H}$ bond length is calculated as $1.012 \AA$ in vacuum and $1.013 \AA$ in the solvent media, but experimental value is $0.856 \AA$. Similarly, $\mathrm{C}-\mathrm{H}$ bond lengths are an average of 1.080-1.090 $\AA$ for the structure while experimental values are between of 0.891-1.064 Å. The reason of these deviations is low scattering factors of hydrogen atoms in X-ray diffraction.

Figure 1 shows an intramolecular hydrogen bond between nitrogen and hydrogen atoms for $\mathrm{tbH}$. The distance between the $13 \mathrm{~N}$ and $10 \mathrm{H}$ atoms is $2.46 \AA$. It is well known that this distance between the nitrogen and hydrogen atoms indicates the intramolecular hydrogen bonding (Brandle et al. 2001). Since the distance between $70-12 \mathrm{H}$ is $2.75 \AA$ and the distance between $8 \mathrm{H}-160$ is $2.99 \AA$, we do not think that there are intramolecular hydrogen bonds between the atoms. As with bond lengths, the solvent medium also affects the bond angles, but most of the angles are consistent with the experimental values. In addition, Table 1 shows that the geometric parameters calculated in the polar and non-polar solvent environments are different from each other. This indicates that different polarities lead to the formation of different geometric structures.

\subsection{Vibrational frequencies and assignment}

tbH has 21 atoms and 57 vibrational modes. All of the calculated frequencies and intensities are given in Table 2 together with experimental data. Theoretical calculations were carried out under the harmonic approximation by using B3LYP level with $6-311++G(d, p)$ basis set. The experimental IR spectrum of $\mathrm{tbH}$ in solid phase is also presented in Figure 2. 
Table 2. Vibrational frequencies and assignments of tbH in different media.

\begin{tabular}{|c|c|c|c|c|c|c|c|c|c|c|}
\hline \multirow{2}{*}{ Mode } & \multirow{2}{*}{ Exp. } & \multicolumn{2}{|c|}{ Vacuum } & \multicolumn{2}{|c|}{ DCM } & \multicolumn{2}{|c|}{ DMSO } & \multicolumn{2}{|c|}{$\mathrm{H}_{2} \mathrm{O}$} & \multirow{2}{*}{ (\%) PED } \\
\hline & & Freq. & IR & Freq. & $I_{\mathbb{R}}$ & Freq. & $\mathrm{I}_{\mathrm{IR}}$ & Freq. & $I_{\mathbb{R}}$ & \\
\hline 1 & - & 28 & 0.00 & 42 & 0.00 & 35 & 0.00 & 33 & 0.00 & $\Gamma_{H C N C}(74)+\Gamma_{C C C N}(13)$ \\
\hline 2 & - & 55 & 0.13 & 67 & 0.20 & 73 & 0.21 & 74 & 0.21 & $\Gamma_{\mathrm{HCNC}}(41)+\Gamma_{\operatorname{cCCN}}(39)$ \\
\hline 3 & - & 91 & 0.01 & 94 & 0.02 & 94 & 0.03 & 94 & 0.03 & $\Gamma_{N C N C}(54)+\Gamma_{C N C C}(11)$ \\
\hline 4 & - & 107 & 0.21 & 112 & 0.12 & 113 & 0.12 & 113 & 0.12 & $\Gamma_{C C C N}(36)+\Gamma_{N C N C}(24)$ \\
\hline 5 & - & 138 & 0.61 & 146 & 0.45 & 146 & 0.44 & 146 & 0.44 & $\Gamma_{N C N C}(44)+\Gamma_{C N C C}(30)$ \\
\hline 6 & - & 186 & 0.32 & 193 & 0.26 & 194 & 0.26 & 194 & 0.26 & $\Gamma_{C C C N}(41)+\Gamma_{N C N C}(36)$ \\
\hline 7 & - & 204 & 1.29 & 203 & 1.08 & 204 & 1.04 & 204 & 1.04 & $\delta_{C N C}(34)+\delta_{N C N}(28)$ \\
\hline 8 & - & 218 & 0.22 & 224 & 0.19 & 225 & 0.20 & 225 & 0.20 & $\Gamma_{\operatorname{cccN}}(52)+\Gamma_{\mathrm{CNCN}}(13)$ \\
\hline 9 & - & 296 & 0.20 & 295 & 0.19 & 296 & 0.19 & 296 & 0.19 & $\delta_{C N C}(69)$ \\
\hline 10 & - & 341 & 0.01 & 346 & 0.00 & 347 & 0.00 & 348 & 0.00 & $\Gamma_{C N C N}(35)+\Gamma_{N C N C}(30)$ \\
\hline 11 & - & 360 & 1.58 & 360 & 1.46 & 359 & 1.49 & 359 & 1.49 & $\delta_{O C N}(35)+\delta_{C N C}(33)$ \\
\hline 12 & - & 388 & 0.37 & 387 & 0.24 & 387 & 0.26 & 387 & 0.26 & $\delta_{O C N}(31)+\delta_{C N C}(17)+V_{C N}(11)$ \\
\hline 13 & - & 432 & 2.80 & 434 & 2.31 & 434 & 2.31 & 434 & 2.31 & $\delta_{C N C}(34)+\delta_{N C N}(14)+V_{C N}(11)$ \\
\hline 14 & - & 493 & 1.87 & 498 & 1.61 & 497 & 1.60 & 497 & 1.60 & $\delta_{C N C}(16)+\delta_{N C N}(12)$ \\
\hline 15 & $555 \mathrm{vw}$ & 584 & 0.88 & 586 & 0.73 & 585 & 1.29 & 585 & 1.40 & $V_{C N}(66)$ \\
\hline 16 & $572 v w$ & 589 & 0.00 & 587 & 0.50 & 586 & 0.74 & 586 & 0.74 & $\Gamma_{\operatorname{CnCN}}(50)+\Gamma_{\text {HNCCC}}(16)$ \\
\hline 17 & $614 \mathrm{~s}$ & 611 & 8.85 & 602 & 6.84 & 599 & 6.33 & 599 & 6.25 & $\Gamma_{\text {HNCC }}(70)+\Gamma_{\text {CNCN }}(18)$ \\
\hline 18 & - & 658 & 0.81 & 660 & 0.66 & 660 & 0.67 & 660 & 0.68 & $\delta_{N C N}(34)+V_{C N}(21)$ \\
\hline 19 & $681 \mathrm{~s}$ & 689 & 1.38 & 687 & 0.89 & 686 & 0.88 & 686 & 0.88 & $\Gamma_{\text {ONCCC}}(35)+\Gamma_{N C N C}(25)+\Gamma_{C C N C}(20)$ \\
\hline 20 & $731 \mathrm{~s}$ & 709 & 1.45 & 709 & 1.44 & 709 & 1.44 & 709 & 1.44 & $\delta_{O C N}(53)+\delta_{N C N}(13)$ \\
\hline 21 & $750 \mathrm{~s}$ & 726 & 4.79 & 726 & 3.33 & 726 & 3.30 & 726 & 3.30 & $\Gamma_{\text {ONNC }}(66)$ \\
\hline 22 & $762 m$ & 734 & 0.14 & 735 & 0.22 & 735 & 0.25 & 735 & 0.26 & $\Gamma_{\text {ONCC }}(47)+\Gamma_{\text {ONNC }}(23)+\Gamma_{C C N C}(19)$ \\
\hline 23 & $783 \mathrm{~m}$ & 757 & 0.76 & 756 & 0.35 & 755 & 0.32 & 755 & 0.32 & $V_{C N}(32)+\delta_{C N C}(16)$ \\
\hline 24 & $860 \mathrm{~s}$ & 813 & 1.40 & 833 & 0.87 & 837 & 0.85 & 837 & 0.84 & $\Gamma_{H C N C}(85)+\Gamma_{C N C N}(12)$ \\
\hline 25 & $940 \mathrm{vw}$ & 914 & 0.80 & 916 & 0.67 & 916 & 0.66 & 916 & 0.66 & $\delta_{C N C}(25)+V_{C N}(13)$ \\
\hline 26 & - & 1015 & 0.36 & 1017 & 0.74 & 1017 & 0.82 & 1017 & 0.83 & $V_{C N}(21)+\delta_{C N C}(18)$ \\
\hline 27 & $1041 w$ & 1045 & 2.02 & 1047 & 1.81 & 1047 & 1.85 & 1047 & 1.86 & $\Gamma_{H C N C}(38)+V_{C N}(17)+\delta_{N C N}(15)$ \\
\hline 28 & $1071 w$ & 1094 & 7.45 & 1097 & 7.12 & 1097 & 7.27 & 1097 & 7.28 & $V_{C N}(48)+\delta_{C C N}(10)$ \\
\hline 29 & - & 1110 & 0.00 & 1110 & 0.00 & 1109 & 0.01 & 1109 & 0.01 & $\Gamma_{H C N C}(69)+\delta_{H C H}(30)$ \\
\hline 30 & - & 1113 & 0.21 & 1110 & 0.01 & 1110 & 0.00 & 1110 & 0.00 & $\Gamma_{\mathrm{HCNC}}(61)+\delta_{\mathrm{HCH}}(20)$ \\
\hline 31 & $1140 w$ & 1139 & 0.68 & 1137 & 0.63 & 1138 & 0.73 & 1138 & 0.74 & $V_{C N}(35)+\Gamma_{H C N C}(12)$ \\
\hline 32 & $1173 m$ & 1185 & 1.66 & 1189 & 2.02 & 1187 & 2.12 & 1187 & 2.12 & $\delta_{H C N}(30)+V_{C N}(10)$ \\
\hline 33 & $1222 \mathrm{~s}$ & 1211 & 10.52 & 1212 & 10.58 & 1211 & 10.67 & 1211 & 10.68 & $\delta_{H C N}(30)+V_{C N}(15)+\delta_{N C N}(10)$ \\
\hline 34 & - & 1256 & 4.01 & 1261 & 3.79 & 1262 & 3.86 & 1262 & 3.87 & $V_{C N}(40)+\delta_{C N C}(20)$ \\
\hline 35 & $1293 m$ & 1296 & 3.64 & 1295 & 1.83 & 1294 & 1.77 & 1294 & 1.77 & $V_{C N}(38)$ \\
\hline 36 & $1334 \mathrm{~m}$ & 1334 & 6.28 & 1335 & 6.88 & 1335 & 7.37 & 1335 & 7.43 & $V_{C N}(32)+\delta_{N C N}(14)$ \\
\hline 37 & $1366 \mathrm{~m}$ & 1359 & 3.06 & 1361 & 4.14 & 1360 & 4.34 & 1360 & 4.35 & $\delta_{H N C}(46)$ \\
\hline 38 & - & 1370 & 2.04 & 1369 & 0.25 & 1369 & 0.12 & 1369 & 0.11 & $V_{C N}(20)+\delta_{H N C}(13)$ \\
\hline 39 & $1410 \mathrm{~m}$ & 1402 & 5.92 & 1399 & 6.56 & 1398 & 6.54 & 1398 & 6.53 & $\delta_{H C H}(47)+V_{C N}(11)$ \\
\hline 40 & - & 1409 & 1.00 & 1406 & 0.23 & 1405 & 0.21 & 1405 & 0.21 & $\delta_{\mathrm{HCH}}(39)$ \\
\hline 41 & $1423 m$ & 1429 & 1.29 & 1425 & 0.99 & 1423 & 0.99 & 1423 & 0.99 & $\delta_{H C H}(72)+\Gamma_{H C N C}(20)$ \\
\hline 42 & $1454 s$ & 1436 & 16.24 & 1431 & 0.86 & 1429 & 0.88 & 1429 & 0.89 & $\delta_{\mathrm{HCH}}(44)$ \\
\hline 43 & - & 1440 & 2.96 & 1432 & 10.80 & 1430 & 10.31 & 1430 & 10.27 & $\delta_{H C H}(62)+\Gamma_{H C N C}(13)$ \\
\hline 44 & - & 1462 & 1.93 & 1453 & 4.86 & 1451 & 4.99 & 1451 & 4.99 & $\delta_{H C H}(63)+\Gamma_{H C N C}(10)$ \\
\hline 45 & $1487 m$ & 1474 & 2.77 & 1470 & 3.66 & 1470 & 4.08 & 1470 & 4.13 & $\delta_{H C H}(46)+V_{C N}(16)$ \\
\hline
\end{tabular}


Table 2 (continuation). Vibrational frequencies and assignments of tbH in different media

\begin{tabular}{ccccccccccc}
\hline 46 & $1546 \mathrm{~s}$ & 1521 & 14.69 & 1518 & 11.84 & 1517 & 12.21 & 1517 & 12.26 & $\delta_{C C N}(30)+V_{C-C}(19)+V_{C N}(13)$ \\
47 & $1591 \mathrm{~s}$ & 1557 & 15.48 & 1550 & 12.40 & 1548 & 12.41 & 1548 & 12.42 & $V_{C=C}(49)+V_{C N}(23)$ \\
48 & $1661 \mathrm{vs}$ & 1695 & 100.00 & 1643 & 100.00 & 1633 & 100.00 & 1632 & 100.00 & $V_{C O}(63)$ \\
49 & $1687 \mathrm{vs}$ & 1706 & 78.75 & 1664 & 62.87 & 1656 & 64.68 & 1655 & 64.87 & $V_{C O}(72)$ \\
50 & - & 2952 & 3.90 & 2960 & 2.60 & 2960 & 2.53 & 2960 & 2.53 & $V_{C H 35 y}(99)$ \\
51 & - & 2958 & 2.79 & 2963 & 1.60 & 2964 & 1.55 & 2964 & 1.54 & $V_{C H 35 y}(100)$ \\
52 & - & 3020 & 1.27 & 3022 & 1.06 & 3022 & 1.08 & 3022 & 1.08 & $V_{C H 3 A S y}(99)$ \\
53 & $3014 \mathrm{~m}$ & 3027 & 0.63 & 3034 & 0.54 & 3035 & 0.57 & 3035 & 0.58 & $V_{C H 3 A S_{Y}}(99)$ \\
54 & - & 3040 & 0.75 & 3051 & 0.43 & 3052 & 0.41 & 3052 & 0.41 & $V_{C H 3 A S_{Y}}(100)$ \\
55 & - & 3062 & 0.04 & 3069 & 0.03 & 3070 & 0.04 & 3071 & 0.04 & $V_{C H 3 A S Y}(98)$ \\
56 & $3113 \mathrm{w}$ & 3137 & 0.23 & 3144 & 0.21 & 3145 & 0.20 & 3145 & 0.20 & $V_{C H}(99)$ \\
57 & $3150 \mathrm{w}$ & 3482 & 9.46 & 3475 & 6.94 & 3474 & 6.80 & 3474 & 6.79 & $V_{N H}(100)$ \\
\hline
\end{tabular}

vs: very strong; s: strong; m: medium; w: weak; vw; very weak, $v$ : stretching mode, $\delta$ : bending mode, $\Gamma$ : torsional mode

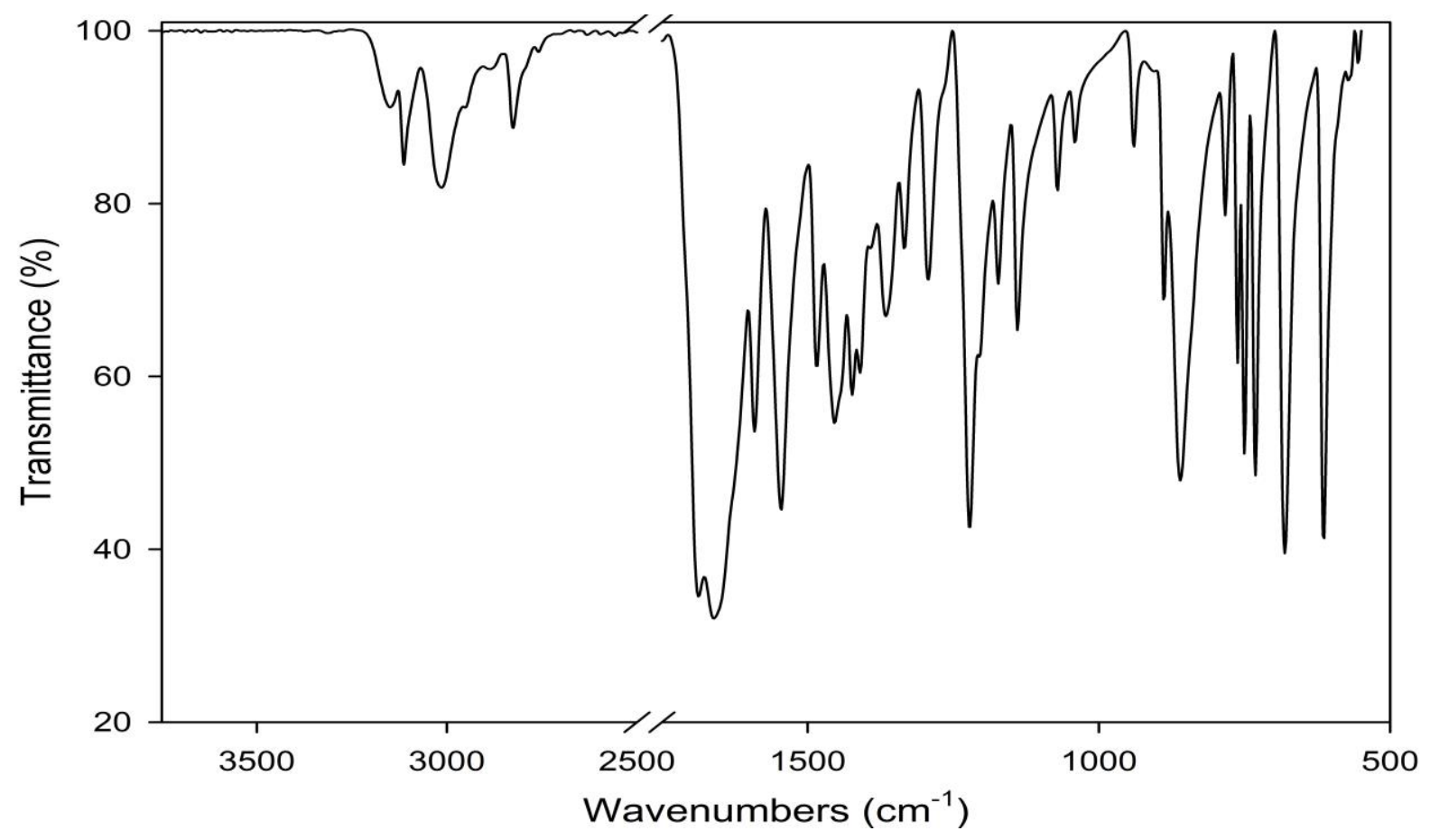

Figure 2. Experimental IR spectrum of tbH.

Small changes due to solvent effects in geometric parameters cause more serious effects on vibrational frequencies. When the effects of solvent environments on the vibrational frequency of any molecule are examined, some changes are expected. These changes are primarily shifts in the vibration frequencies due to solvent effects. Secondly, the increase or decrease in the intensity of vibration frequencies occurs. In Figures 3 and 4, these situations are evident. With increased $\varepsilon$, shifts in frequencies have occurred and the intensities of the vibration frequencies have increased significantly. The calculated IR spectra of tbH are also simulated in Figure 3 and Figure 4.

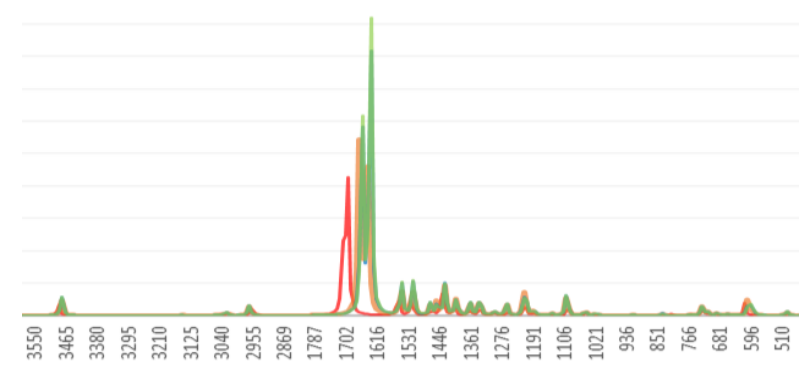


Figure 3. The comparison of theoretical IR spectra of tbH in various media.

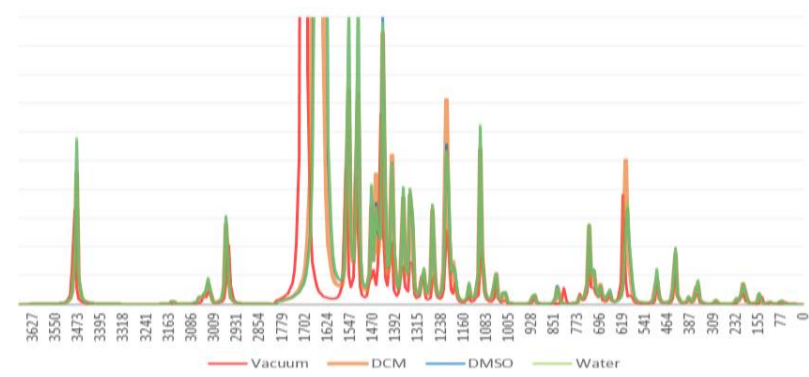

Figure 4. The comparison of theoretical IR spectra of tbH in various media (at close scale).

$\mathrm{N}-\mathrm{H}$ stretching modes are seen at $3300-3500 \mathrm{~cm}^{-1}$ for free $\mathrm{N}-\mathrm{H}$ bond. If $\mathrm{N}-\mathrm{H}$ is bonded with the hydrogen bond, this value is decreased until 3100$3200 \mathrm{~cm}^{-1}$. In this study, the calculated $\mathrm{N}-\mathrm{H}$ stretching modes are seen at $3482(\varepsilon=1.00), 3475$ ( $\varepsilon=8.93), 3474(\varepsilon=46.83)$ and $3474(\varepsilon=78.36) \mathrm{cm}^{-1}$ as medium intensities, but this mode is seen in the solid phase experimental spectrum at $3150 \mathrm{w}$. In this case, it can be said that tbH has a bonded $\mathrm{N}-\mathrm{H}$ stretching mode and therefore it may be dimeric structure in solid phase. The $\mathrm{C}-\mathrm{H}$ stretching bands are found at $2900-3200 \mathrm{~cm}^{-1}$ region. The all of $\mathrm{C}-\mathrm{H}$ stretching mode of $\mathrm{tbH}$ have been observed at 3113 $\mathrm{cm}^{-1}$ as weak in the experimental spectrum. These modes were calculated at 3137, 3144, 3145 and $3145 \mathrm{~cm}^{-1}$, respectively, in vacuum and in solvent media. At the same time, tbH contains two methyl groups. The symmetric and asymmetric $\mathrm{CH}_{3}$ stretching modes of the methyl groups are detailed in Table 2. Additionally, $\mathrm{C}=\mathrm{O}$ vibrations give important information about the structure of $\mathrm{tbH}$. $\mathrm{C}=\mathrm{O}$ stretching modes of this structure are calculated at 1706 and $1695 \mathrm{~cm}^{-1}$ for vacuum while experimental values are $1691 \mathrm{vs}$ and $1667 \mathrm{vs}$. In the DCM non-polar solvent, these modes are calculated at 1664 and $1643 \mathrm{~cm}^{-1}$ respectively. In the polar solvents, values of the vibrations are at 1656-1633 and $1655-1632 \mathrm{~cm}^{-1}$. As can be seen from these results, the solvents affect $\mathrm{C}=0$ stretching vibrations of $\mathrm{tbH}$ too much. On the other hand, there is a difference of $26 \mathrm{~cm}^{-1}$ between the $\mathrm{C}=\mathrm{O}$ stretching vibrations as seen from the solid tbH experimental spectrum. However, the difference between the calculated $\mathrm{C}=\mathrm{O}$ stretching vibrations of free $\mathrm{tbH}$ is only $11 \mathrm{~cm}^{-1}$. The reason of this difference is status of $\mathrm{C}=\mathrm{O}$ bonds of $\mathrm{tbH}$ which are different from each other. In summary, we think that solid tbH is in dimeric structure and one of the $\mathrm{C}=\mathrm{O}$ bond of $\mathrm{tbH}$ may be establish a hydrogen bond to other $\mathrm{tbH}$.

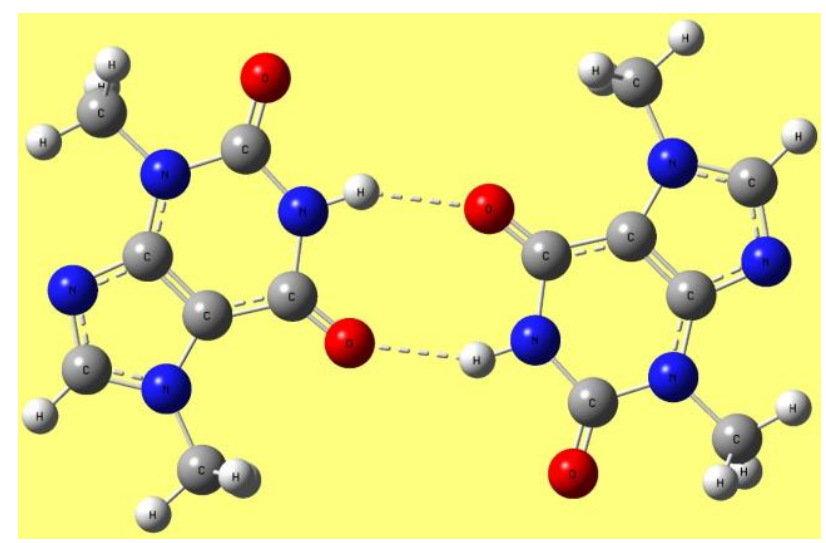

Figure 5. The possible dimer structure of $\mathrm{tbH}$.

In pyrimidine rings, $\mathrm{C}-\mathrm{N}$ and $\mathrm{C}-\mathrm{C}$ vibration modes are seen at 1500-1600 $\mathrm{cm}^{-1}$ region (Breda et al. 2006). In this study $\mathrm{C}-\mathrm{C}, \mathrm{C}=\mathrm{C}$ and $\mathrm{C}-\mathrm{N}$ vibrational modes are calculated at 1557, 1521 and $1474 \mathrm{~cm}^{-1}$ in vacuum. These frequencies and their intensities are shifted seriously in solvent media. For example, in DCM medium, $\mathrm{C}=\mathrm{C}$ stretching mode is calculated at 1550 $\mathrm{cm}^{-1}$. In the other media, it is calculated at $1548 \mathrm{~cm}$ 1. Furthermore, it can be seen that $\mathrm{C}=\mathrm{C}$ stretching mode is more affected by the changing solvent media compared to $\mathrm{C}-\mathrm{C}$ mode. Other calculated $\mathrm{C}-\mathrm{N}$ stretching modes are calculated at 1334, 1296, 1256, 1139, 1094, 1015 and $757 \mathrm{~cm}^{-1}$.

The bending vibrations are generally found at lower wavenumbers compared to stretching modes. $\mathrm{H}-\mathrm{C}$ $\mathrm{N}$ and $\mathrm{H}-\mathrm{N}-\mathrm{C}$ modes are seen in about 1200-1300 $\mathrm{cm}^{-1}$ region in experimental spectrum. These modes were calculated at 1359, 1211 and $1185 \mathrm{~cm}^{-1}$ in vacuum. Similarly, in these modes, frequency shifts are seen in the transition from gas phase to the solvent phase. The bending modes of $\mathrm{C}-\mathrm{N}-\mathrm{C}$ and $\mathrm{N}-$ C-N were calculated at 1045, 1015, 757, 493, 432 and $388 \mathrm{~cm}^{-1}$ with the $\mathrm{N}-\mathrm{C}$ stretching modes. O-C-N bending vibration modes were also computed at 388 and $360 \mathrm{~cm}^{-1}$. In the transition to the solvent environment there are about $1 \mathrm{~cm}^{-1}$ changes in the vibration frequencies. In these regions, there are very few shifts in the transition to solvent 
environments. All calculated data are in agreement with the experimental ones.

Similar to bending modes, torsional modes are also predominantly calculated in low-wavenumbers regions. In this paper, the $\mathrm{H}-\mathrm{C}-\mathrm{N}-\mathrm{C}$ torsional modes in the vacuum environment are predicted at 1113 , 1110, 1045 and $813 \mathrm{~cm}^{-1}$. O-N-C-C and O-N-N-C modes were calculated at 734, 729 and $689 \mathrm{~cm}^{-1}$ in vacuum. These vibrations were also observed in the experimental spectrum in accordance with the calculated values. While the presence of the solvent environments did not cause changes in the vibrational frequencies of some modes, it can cause severe changes in the vibrational frequencies of some modes.

\subsection{The energetic and thermochemical properties of $t b H$}

In Table 3, energies of tbH from DFT-PCM optimizations are presented in vacuum and solvent media. As seen from Table 3, with the increasing dielectric constant of media, energies of $\mathrm{tbH}$ in different solvent media have decreased. Thermochemical properties of $\mathrm{tbH}$ in different solvent media were also calculated and given in Table 3. The thermochemical analysis calculations were performed at $298.15 \mathrm{~K}$ temperature and 1.0 atm pressure. The calculated zero point vibrational energies of $\mathrm{tbH}$ in different media are 100.3394 $\mathrm{Kcal} / \mathrm{mol}$ (vacuum $\varepsilon=1.00$ ), $100.3248 \mathrm{Kcal} / \mathrm{mol}$ (DCM $\varepsilon=8.93), 100.2798 \mathrm{Kcal} / \mathrm{mol}$ (DMSO $\varepsilon=46.83$ ) and $100.2731 \mathrm{Kcal} / \mathrm{mol}$ (water $\mathcal{E}=78.36$ ). Increasing dielectric constants increase the dipole moment of $\mathrm{tbH}$.

Table 3. The energies and thermochemical properties of $\mathrm{tbH}$ in $298.15 \mathrm{~K}$ calculated by DFT.
In addition, some of the important thermal parameters such as entropy and heat capacity have increased as the dielectric constant of medium increases, but the values of these parameters were decreased in the solvent environment when compared to the gas phase.

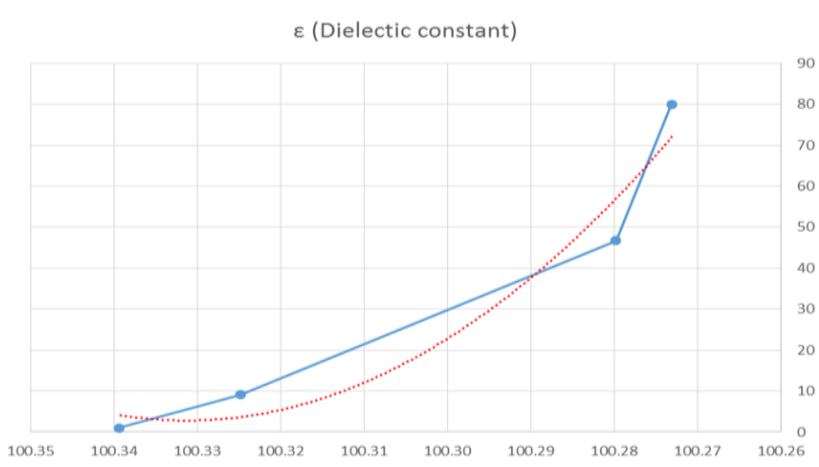

Figure 6. With increasing dielectric constant, energy exchanges of $\mathrm{tbH}$.

\subsection{Frontier molecular orbitals and chemical reactivity}

In this work, we have also computed the highest occupied molecular orbital energies (HOMO), lowest unoccupied molecular orbital energies (LUMO) and their energy gaps for tbH. The gap between HOMO and LUMO energies is an important parameter in detection of molecular electrical transport (Breda et al. 2006, Shahidha et al. 2015) Moreover, the energy of the HOMO is directly related to the ionization potential, and LUMO energy is directly related to the electron affinity. This is used by the frontier electron density for estimating the most reactive position in p-electron systems and it is also explains several types of reaction in conjugated system (Shahidha et al. 2015).

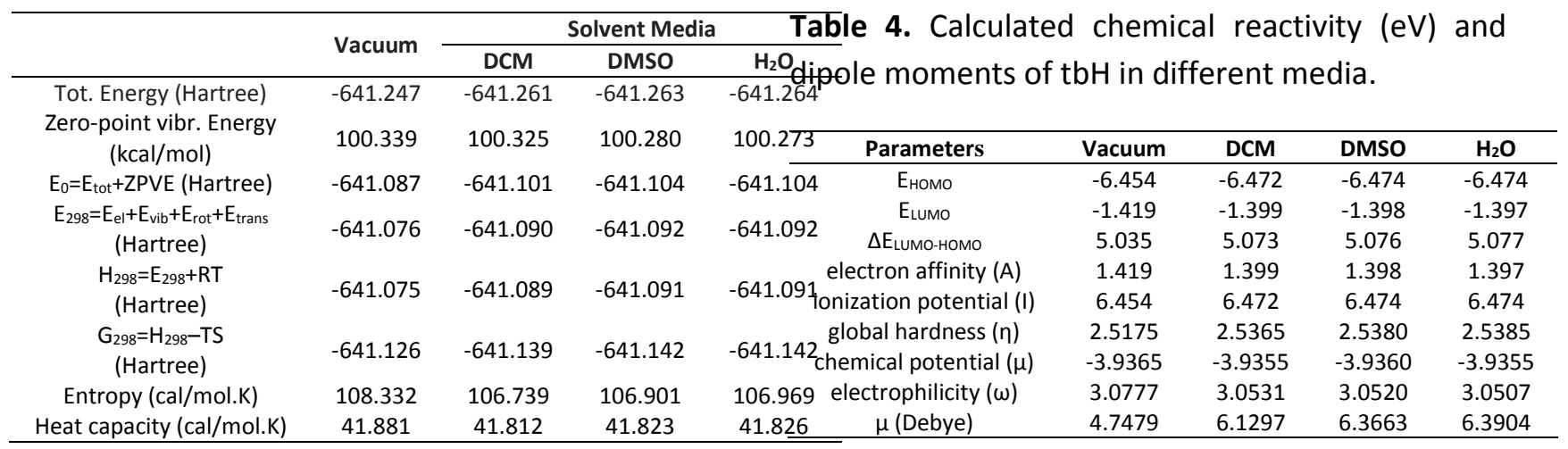


Table 4 shows the calculated electronic properties of $\mathrm{tbH}$ in different dielectric media. When Table 4 is examined, it is seen that HOMO energy increases and LUMO energy decreases with increasing dielectric constant of the environment.

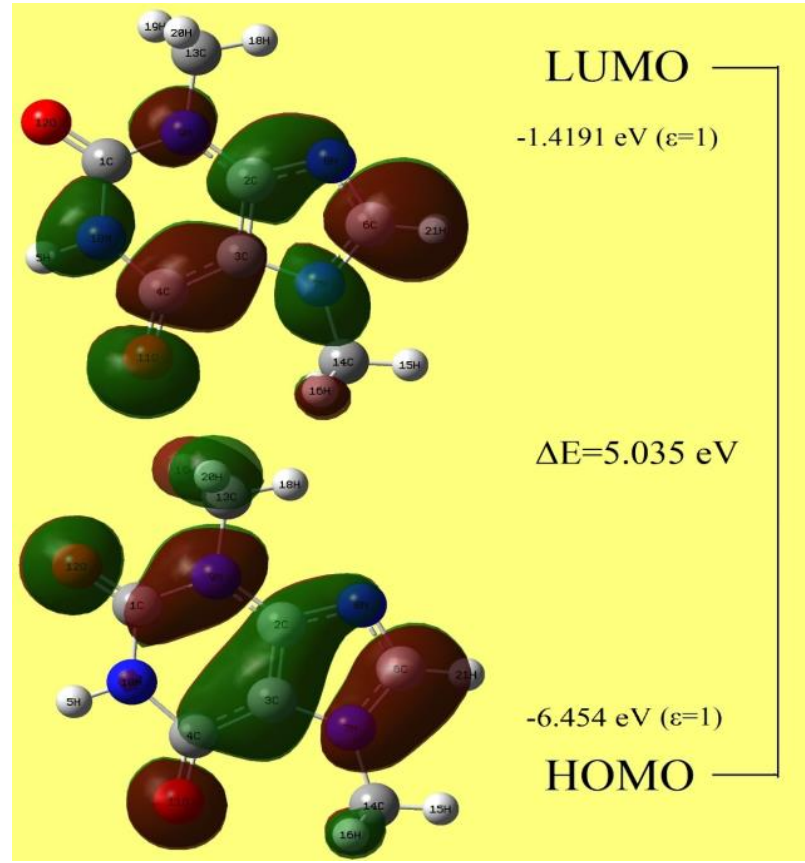

Figure 7. The HOMO-LUMO contour maps of tbH.

Figure 7 shows HOMO and LUMO contour maps of tbH in vacuum medium.

Considering Koopmans's theorem (Parr and Pearson 1983) ionization potential $\mathrm{I}=-\mathrm{E}_{\text {номо }}$ and electron affinity $A=-E_{\text {Lumo }}$ can be described. Parr et al. explained to chemical potential as $\mu=\left(E_{\text {Hомо }}+E_{\text {LUMO }}\right) / 2$, global hardness as $\eta=\left(E_{\text {LUMO }}-\right.$ $\left.E_{\text {номо }}\right) / 2$ and finally electrophilicity as $\omega=\mu^{2} / 2 \eta$ (Brandl et al. 2001, Parr and Pearson 1983, Parr 1999).

\subsection{Atomic charges}

The net atomic charges of tbH atoms calculated by Mulliken Population Analysis (MPA) and Natural Population Analysis (NPA) are given in Table 5. Natural atomic charges are more reliable than those calculated by Mulliken (Breda et al. 2006). The charge distributions of tbH show that all nitrogen atoms are negative while the hydrogen atoms are positive. In addition, the atomic charges of oxygen atoms are rich in negative charges. For the $2 \mathrm{C}$ atom, the Mulliken atomic charge is negative, but the natural charge is positive. In addition, the solvent medium significantly affects the atomic charge of tbH.

Table 5. The Mulliken and Natural atomic charges (in e) of tbH.

\begin{tabular}{ccccccccc}
\hline \multicolumn{1}{c}{ Vacuum } & \multicolumn{2}{c}{ DCM } & \multicolumn{2}{c}{ DMSO } & \multicolumn{2}{c}{$\mathrm{H}_{2} \mathbf{O}$} \\
\hline \multirow{2}{*}{ Atom } & Mlkn & Ntrl & Mlkn & Ntrl & Mlkn & Ntrl & Mlkn & Ntrl \\
& Chrg & Chrg & Chrg & Chrg & Chrg & Chrg & Chrg & Chrg \\
\hline 1C & 0.36 & 0.82 & 0.39 & 0.83 & 0.40 & 0.83 & 0.40 & 0.83 \\
2N & -0.17 & -0.48 & -0.15 & -0.47 & -0.15 & -0.46 & -0.15 & -0.46 \\
3C & -0.09 & 0.38 & -0.06 & 0.39 & -0.05 & 0.39 & -0.05 & 0.39 \\
4C & -0.05 & -0.03 & -0.04 & -0.03 & 0.04 & -0.03 & 0.04 & -0.03 \\
$5 \mathrm{C}$ & -0.07 & -0.64 & -0.05 & -0.64 & -0.05 & -0.65 & -0.05 & -0.65 \\
$6 \mathrm{~N}$ & -0.43 & -0.64 & -0.42 & -0.63 & -0.42 & -0.63 & -0.42 & -0.63 \\
70 & -0.34 & -0.63 & -0.42 & -0.67 & -0.43 & -0.68 & -0.43 & -0.68 \\
$8 \mathrm{H}$ & 0.39 & 0.42 & 0.40 & 0.43 & 0.40 & 0.43 & 0.40 & 0.43 \\
$9 \mathrm{C}$ & -0.27 & -0.36 & -0.29 & -0.36 & -0.29 & -0.36 & -0.29 & -0.36 \\
$10 \mathrm{H}$ & 0.18 & 0.22 & 0.18 & 0.22 & 0.18 & 0.22 & 0.18 & 0.22 \\
$11 \mathrm{H}$ & 0.19 & 0.22 & 0.20 & 0.21 & 0.20 & 0.21 & 0.20 & 0.21 \\
$12 \mathrm{H}$ & 0.20 & 0.20 & 0.20 & 0.21 & 0.20 & 0.21 & 0.20 & 0.21 \\
$13 \mathrm{~N}$ & -0.20 & -0.53 & -0.27 & -0.55 & -0.28 & -0.55 & -0.28 & -0.55 \\
$14 \mathrm{C}$ & 0.24 & 0.26 & 0.25 & 0.28 & 0.25 & 0.28 & 0.25 & 0.28 \\
$15 \mathrm{~N}$ & -0.13 & -0.37 & -0.11 & -0.36 & -0.10 & -0.36 & -0.10 & -0.36 \\
$16 \mathrm{O}$ & -0.34 & -0.62 & -0.40 & -0.66 & -0.42 & -0.66 & -0.42 & -0.66 \\
$17 \mathrm{C}$ & -0.30 & -0.35 & -0.31 & -0.35 & -0.31 & -0.35 & -0.31 & -0.35 \\
$18 \mathrm{H}$ & 0.13 & 0.20 & 0.15 & 0.22 & 0.16 & 0.22 & 0.16 & 0.22 \\
$19 \mathrm{H}$ & 0.21 & 0.22 & 0.20 & 0.22 & 0.21 & 0.22 & 0.21 & 0.22 \\
$20 \mathrm{H}$ & 0.21 & 0.22 & 0.20 & 0.22 & 0.21 & 0.22 & 0.21 & 0.22 \\
$21 \mathrm{H}$ & 0.22 & 0.20 & 0.25 & 0.21 & 0.26 & 0.21 & 0.26 & 0.22 \\
\hline & & & & & & & &
\end{tabular}

\section{6. $\mathrm{tbH}-\mathrm{H}_{2} \mathrm{O}$ complexes}

As we mentioned in the introduction of this paper, the most basic situation in the investigation of solvent effects on biological molecules is to consider water complexes. Hydrogen bonded complexes form between a hydrogen atom attached to an electronegative donor atom and a neighboring acceptor atom. Here, hydrogen bonded $t b H-H_{2} \mathrm{O}$ complexes were studied using the DFT/B3LYP method. Since the tbH molecule has $\mathrm{N}$ and $\mathrm{O}$ heteroatoms and therefore lone pair (Ip) electrons, it can form intermolecular $\mathrm{H}$-bonds of the type $\mathrm{IpN} \cdots \mathrm{H}-\mathrm{O}$ and IpO $\cdots \mathrm{H}-\mathrm{O}$ with $\mathrm{H}_{2} \mathrm{O}$ molecules. The $\mathrm{tbH}-\mathrm{H}_{2} \mathrm{O}$ complexes investigated in this study were studied for the presence of a maximum of eight water molecules adjacent to tbH in the presence of hydrogen bonding. Nine versions have been proposed for one-two $\mathrm{H}_{2} \mathrm{O}$ bonding states, and for these versions, energies and hydrogen bond lengths have been investigated. 

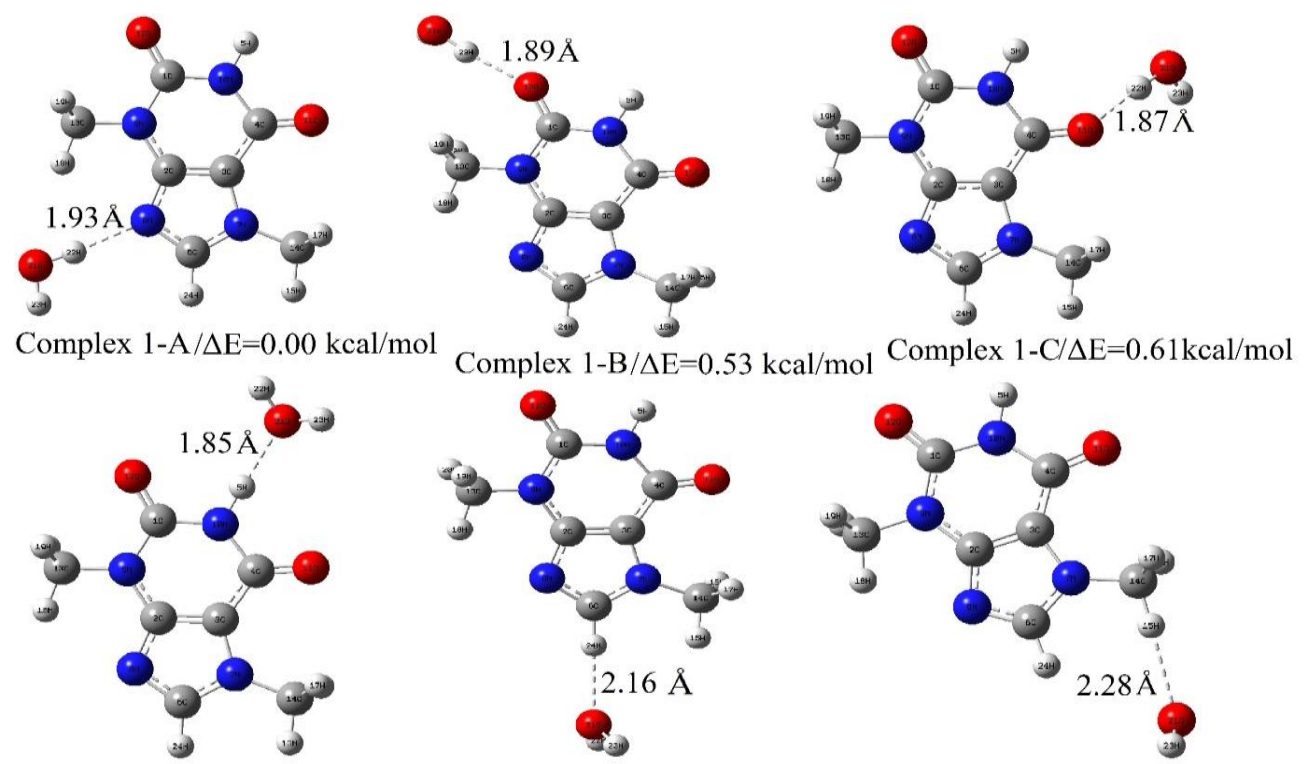

Complex $1-\mathrm{D} / \Delta \mathrm{E}=0.78 \mathrm{kcal} / \mathrm{mol}$ Complex $1-\mathrm{E} / \Delta \mathrm{E}=1.22 \mathrm{kcal} / \mathrm{mol}$ Complex $1-\mathrm{F} / \Delta \mathrm{E}=1.49 \mathrm{kcal} / \mathrm{mol}$
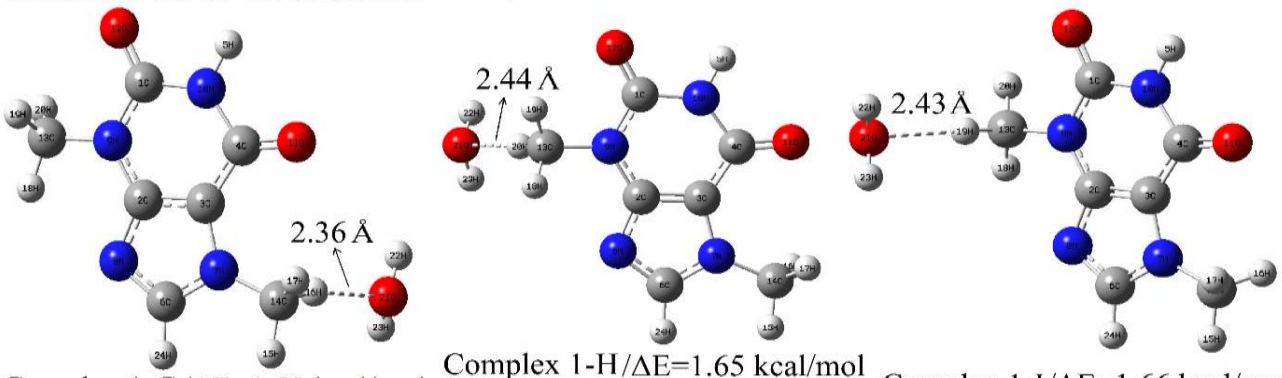

Complex $1-\mathrm{G} / \Delta \mathrm{E}=1.58 \mathrm{kcal} / \mathrm{mol}$

Complex $1-\mathrm{H} / \Delta \mathrm{E}=1.65 \mathrm{kcal} / \mathrm{mo}$

Complex $1-\mathrm{l} / \Delta \mathrm{E}=1.66 \mathrm{kcal} / \mathrm{mol}$

Figure 8. The optimized structures of $1-1$ bonded $\mathrm{tbH}-\mathrm{H}_{2} \mathrm{O}$ complexes

Figure 8 shows that the most stable structure of 1-1 bonded $\mathrm{tbH}-\mathrm{H}_{2} \mathrm{O}$ complexes is the 1-A complex. This structure has an IpN $\cdots \mathrm{H}-\mathrm{O}$ type intermolecular $\mathrm{H}$ bond and length of this bond was calculated to be $1.93 \AA$. When examined in terms of energy, the lowest energetic versions of the 1-1 tbH complexes are those hydrogens bonded ones in the form of IpN $\cdots \mathrm{H}-\mathrm{O}$ and IpO $\cdots \mathrm{H}-\mathrm{O}$. It is known that hydrogen bonds of these types are strong. On the other hand, the common point of these three versions is that hydrogen atoms of water molecules are bonded to oxygen and nitrogen atoms of tbH but in other versions, hydrogen bonds are formed between oxygen atoms of water molecule and hydrogen atoms of $\mathrm{tbH}$. Therefore, for the other versions it can be said that bond strength is weaker and bond lengths are taller. 1-2 bonded tbH- $\mathrm{H}_{2} \mathrm{O}$ complexes are seen in Figure 9. The most striking property of these complexes is that the structures with hydrogen bonds of the form IpN $\cdots \mathrm{H}-\mathrm{O}$ and IpO $\cdots \mathrm{H}$ $\mathrm{O}$ are the most stable structures. In all structures, approximate $\mathrm{O}-\mathrm{H} \cdots \mathrm{O}$ distances are 1.88-1.89 $\AA$ and $\mathrm{O}-\mathrm{H} \cdots \mathrm{N}$ distance is $1.94 \AA$. In the $\mathrm{C}-\mathrm{H} \cdots \mathrm{O}$ hydrogen bonds, distances vary between $2.16-2.48 \AA$. 


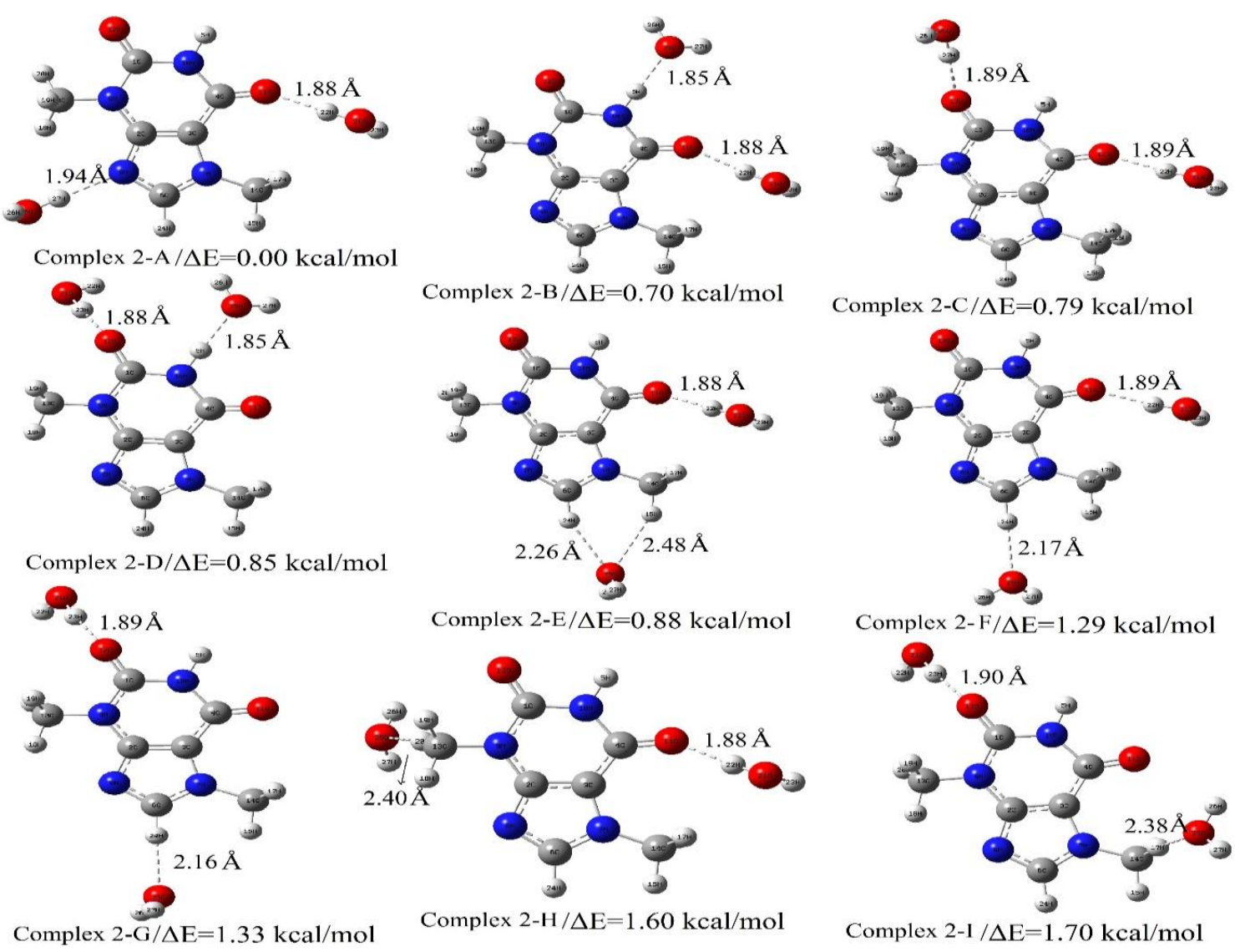

Figure 9. The optimized structures of 1-2 bonded $\mathrm{tbH}-\mathrm{H} 2 \mathrm{O}$ complexes.

Table 6. Total energies (au) and relative energies (kcal/mol) of $\mathrm{tbH}-1 \mathrm{H}_{2} \mathrm{O}, \mathrm{tbH}-2 \mathrm{H}_{2} \mathrm{O}$ and $\mathrm{tbH}-3 \mathrm{H}_{2} \mathrm{O}$ complexes.

\begin{tabular}{ccccccc}
\hline Strc. & $\mathbf{1 - 1}$ Comp. & $\boldsymbol{\Delta}$ & $\mathbf{1 - 2}$ Comp. & $\boldsymbol{\Delta}$ & $\mathbf{1 - 3}$ Comp. & $\boldsymbol{\Delta}$ \\
\hline V1 & -717.74718 & 0.00 & -794.22156 & 0.00 & -870.69601 & 0.00 \\
V2 & -717.74633 & 0.53 & -794.22044 & 0.70 & -870.69599 & 0.02 \\
V3 & -717.74621 & 0.61 & -794.22030 & 0.79 & -870.69555 & 0.29 \\
V4 & -717.74594 & 0.78 & -794.22020 & 0.85 & -870.69532 & 0.44 \\
V5 & -717.74523 & 1.22 & -794.22016 & 0.88 & -870.69463 & 0.87 \\
V6 & -717.74481 & 1.49 & -794.21950 & 1.29 & -870.69452 & 0.94 \\
V7 & -717.74466 & 1.58 & -794.21943 & 1.33 & -870.69428 & 1.09 \\
V8 & -717.74454 & 1.65 & -794.21901 & 1.60 & -870.69348 & 1.59 \\
V9 & -717.74453 & 1.66 & -794.21885 & 1.70 & & \\
\hline
\end{tabular}

Figure 10 shows 1-3 bonded eight different versions of $\mathrm{tbH}-\mathrm{H}_{2} \mathrm{O}$ complexes. As shown in the Figure, the most stable structure among these eight structures is the one with IpN $\cdots \mathrm{H}-\mathrm{O}$ and IpO $\cdots \mathrm{H}-\mathrm{O}$ connections similar to 1-1 and 1-2. Unlike the others, it can be seen from Table 6 that the energy difference between V1 and V2 is very small. Calculated energy difference is only $0.02 \mathrm{kcal} / \mathrm{mol}$. Therefore, from the results of the theoretical calculations, it cannot be clearly determined, which 1-3 connections are favorable?

Table 7. Total energies (au) and relative energies (kcal/mol) of tbH- $4 \mathrm{H}_{2} \mathrm{O}, \mathrm{tbH}-5 \mathrm{H}_{2} \mathrm{O}, \mathrm{tbH}-6 \mathrm{H}_{2} \mathrm{O}, \mathrm{tbH}-7 \mathrm{H}_{2} \mathrm{O}$ and tbH- $8 \mathrm{H}_{2} \mathrm{O}$ complexes. $\left(\Delta=\left|\mathrm{EV}_{1}-\mathrm{EV}_{\mathrm{X}}\right|\right)$

\begin{tabular}{ccccc}
\hline Structure & V1 & V2 & V3 & V4 \\
\hline 1-4 Complex & -947.17031 & -947.16912 & -947.16790 & -947.16755 \\
$\Delta$ & 0.00 & 0.74 & 1.51 & 1.73 \\
$\mathbf{1 - 5}$ Complex & -1023.64276 & -1023.64262 & -1023.64221 & -1023.64209 \\
$\Delta$ & 0.00 & 0.09 & 0.34 & 0.42 \\
$\mathbf{1 - 6}$ Complex & -1100.12024 & - & - & - \\
$\mathbf{1 - 7}$ Complex & -1176.58970 & - & - & - \\
$\mathbf{1 - 8}$ Complex & -1253.06677 & - & - & - \\
\hline
\end{tabular}



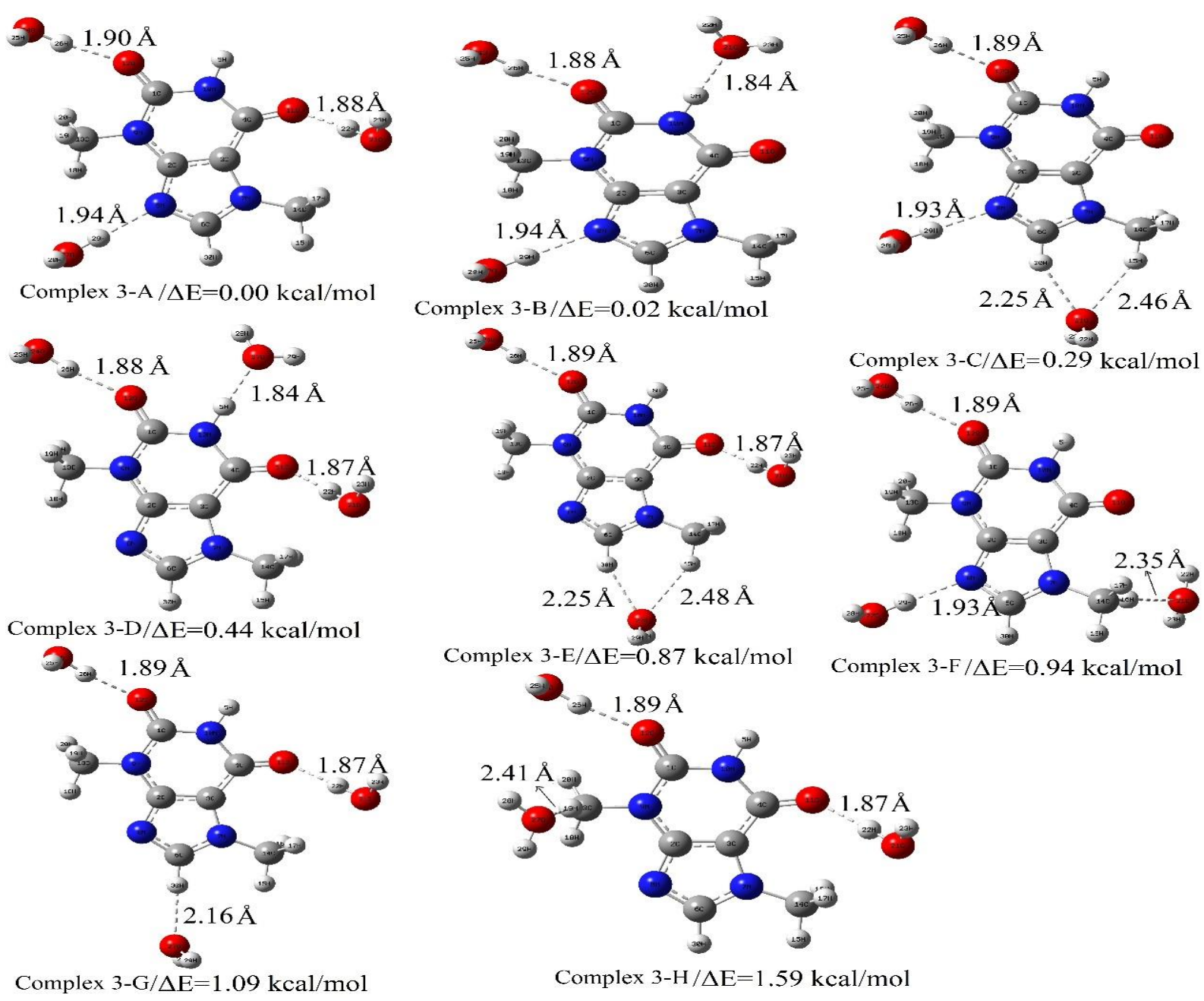

Figure 10. The optimized structures of $1-3$ bonded $\mathrm{tbH}-\mathrm{H}_{2} \mathrm{O}$ complexes.

In Figure 11, possible 1-4, 1-5, 1-6, 1-7 and 1-8 bound $\mathrm{tbH}-\mathrm{H}_{2} \mathrm{O}$ complexes are plotted and the calculated energies and energy differences were given in Table 7. Four different combinations have been proposed for 1-4 bonded complexes. When the most stable versions of these structures are investigated, it is seen that the $\mathrm{N} \cdots \mathrm{H}-\mathrm{O}$ and $\mathrm{O} \cdots \mathrm{H}-\mathrm{O}$ type hydrogen bonded structures are most stable. Total energy of version $4 \mathrm{~A}$ is $0.74 \mathrm{kcal} / \mathrm{mol}$ lower than complex $4 \mathrm{~B}$. The only difference between Complex $4 \mathrm{~B}$ and Complex $4 \mathrm{C}$ is that only one of the 4 water molecules bonded to the tbH is bound by hydrogen bonds from two points. This causes a difference of about $0.77 \mathrm{kcal} / \mathrm{mol}$ in the energy and therefore a more stable structure. Figure 11 also shows $1-5$ bonded $\mathrm{tbH}-\mathrm{H}_{2} \mathrm{O}$ complexes. It is seen that the calculated energy values for 1-5 bonded complexes are very close to each other. Only one version of 1-6, 1-7, and 1-8 complexes were studied. Especially after the addition of the eighth water molecule, it was seen that the optimizations ended when the water molecules were clustered. In 1-6 bonded complex, total energy was calculated as 1100.12024 Hartree. $\mathrm{H}$-bond lengths vary between 1.82-1.88 $\AA$ for $\mathrm{O} \cdots \mathrm{H}-\mathrm{O}, 1.95 \AA$ for $\mathrm{N} \cdots \mathrm{H}-\mathrm{O}$ and 2.40 $\AA$ for $\mathrm{O} \cdots \mathrm{H}-\mathrm{C}$. For the $\mathrm{tbH}-7 \mathrm{H}_{2}$ complex, total energy was calculated as -1176.58970 Hartree. H-bond lengths vary between 1.84-2.42 A. 


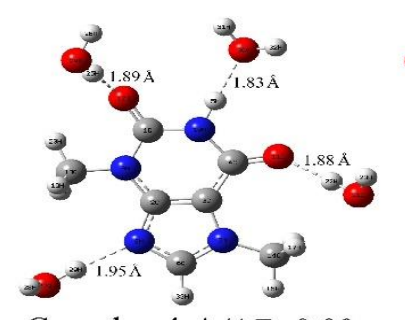

Complex 4-A/ $\Delta \mathrm{E}=0.00$

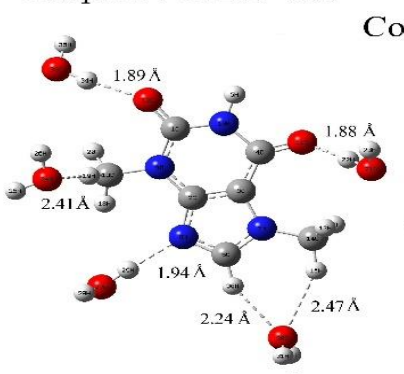

Complex $5-\mathrm{A} / \Delta \mathrm{E}=0.00$

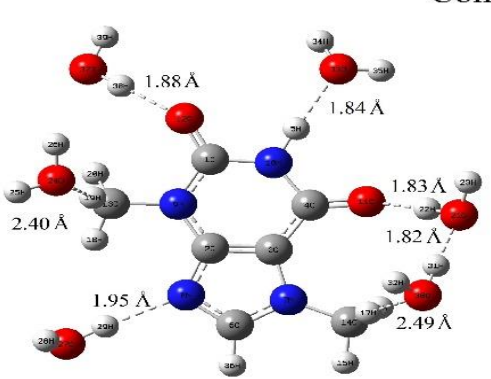

Complex 6

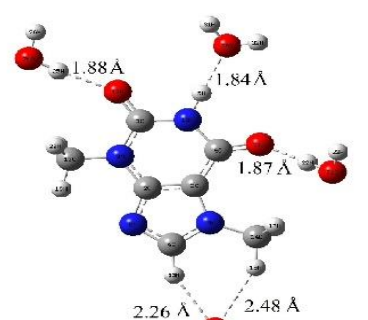

$\rightarrow$

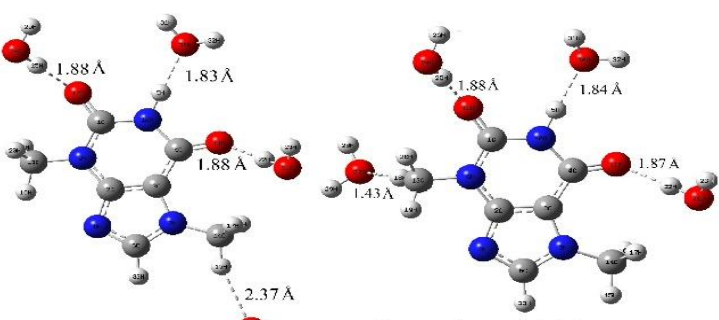

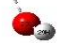

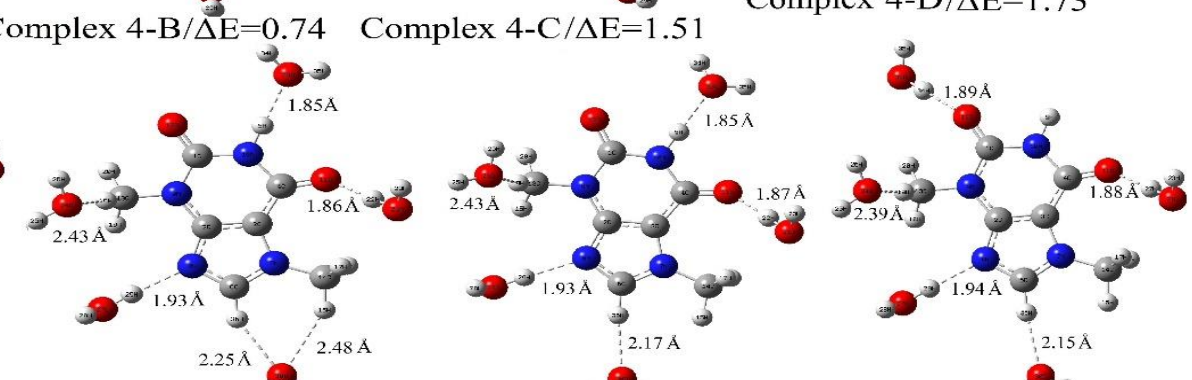

.

8.

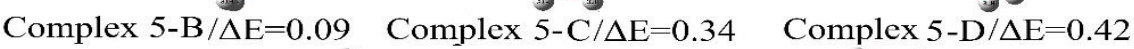

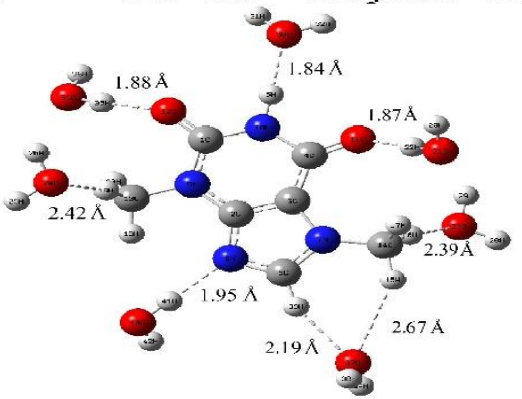

Complex 7

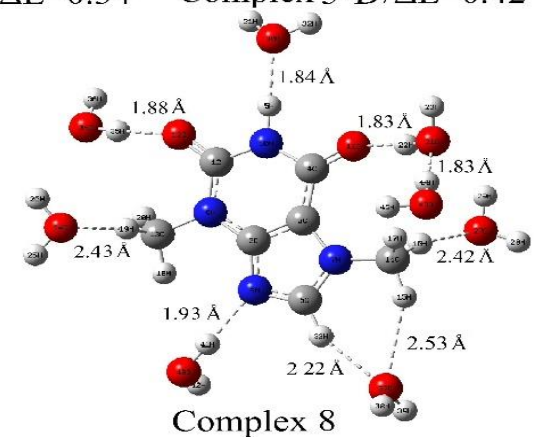

Figure 11. The optimized structures of 1-4, 1-5, 1-6, 1-7 and 1-8 bonded tbH- $\mathrm{H}_{2} \mathrm{O}$ complexes.

\section{Conclusions}

In this paper, we have investigated to the solvent effects on structural, spectroscopic, electronic and thermochemical properties of $\mathrm{tbH}$. The investigations were carried out in DCM, DMSO, $\mathrm{H}_{2} \mathrm{O}$ and vacuum environments. From this study, it can be said that the stable equilibrium energy has reduced in solvent media depending on the dielectric constant. tbH is more stable in the solvent environments. The geometric parameters calculated in non-polar solvent environment and polar solvent environment are different from each other. This case shows that polarity difference of solvents leads to the formation of different geometric structures. For the tbH molecule, vibrational frequencies and their intensities were affected significantly from solvent environments but in the solvents of same polarity shifts were observed minor. While the frontier orbitals of tbH are virtually unaffected by the solvent medium, the atomic charges have affected importantly. It is seen from the results of this study that $\mathrm{N} \cdots \mathrm{H}-\mathrm{O}$ and $\mathrm{O} \cdots \mathrm{H}-$
O hydrogen bonded structures are more stable than others are. Calculated hydrogen bond lengths for all tbH- $\mathrm{H}_{2} \mathrm{O}$ complexes are range from 1.8-2.5 $\AA$.

\section{References}

Bernal-Uruchurtu, M. I., Kerenskaya, G., Janda, K. C., 2009, International Reviews in Physical Chemistry, 28, 223-265.

Bilkan, M. T., 2017. Structural and spectroscopic studies on dimerization and solvent-ligand complexes of Theobromine. Journal of Molecular Liquids, 238, 523532.

Brandl, M., Meyer, M., Sühnel, J. J., 2001. QuantumChemical Analysis of $\mathrm{C}-\mathrm{H} . . . \mathrm{O}$ and $\mathrm{C}-\mathrm{H} . . . \mathrm{N}$ Interactions in RNA Base Pairs-H-Bond Versus Anti-H-Bond Pattern. Journal of biomolecular Structure \& Dynamics, 18, 4, 545-555.

Breda, S., Reva, I.D., Lapinski, L., Nowak, M.J., Fausto, R., 2006. Infrared spectra of pyrazine, pyrimidine and 
pyridazine in solid argon. Journal of Molecular Structures, 786, 193-206.

Calabrese, C., Gou, Q., Spada, L., Maris, A., Caminati, W., Melandri, S. 2016. Effects of Fluorine Substitution on the Microsolvation of Aromatic Azines: The Microwave Spectrum of 3-Fluoropyridine-Water. Journal of Physical Chemistry A, 120, 27, 5163-5168.

Cook, D., Regnier, Z. R., 1967. The infrared spectra of theobromine salts. Canadian Journal of Chemistry, 45, 2899-2902.

Dennington, R. D., Keith, T. A., Millam, J. M. GaussView 5, Gaussian, Inc, 2008.

Ford, K. A., Ebusuzaki, Y., Boyle, P. D., 1998. Methylxanthines. II. Anhydrous Theobromine. Acta Crystallographica, C54, 1980-1983.

Fornaro, T., Burini, D., Biczysko, M., Barone, V. 2015. Hydrogen-Bonding Effects on Infrared Spectra from Anharmonic Computations: Uracil-Water Complexes and Uracil Dimers. Journal of Physical Chemistry A, 119, 4224-4236.

Frisch, M.J., Trucks, G.W., Schlegel, H.B., Scuseria, G.E., Robb, M.A., Cheeseman, J.R., Montgomery Jr., J.A., Vreven, T., Kudin, K.N., Burant, J.C., et al. 2003, Gaussian 03, revision D.01, Gaussian Inc., Wallingford, CT.

Jamróz, M.H., 2004, "Vibrational Energy Distribution Analysis" VEDA 4, Warsaw.

Kwak, K., Rosenfeld, D. E., Chung, J. K., Fayer, M. D, 2008. Solute-Solvent Complex Switching Dynamics of Chloroform between Acetone and Dimethylsulfoxide-Two-Dimensional IR Chemical Exchange Spectroscopy. Journal of Physical Chemistry $B, 112,13906-13915$.

Miertuš, S., Scrocco, E., Tomasi, 1981. Electrostatic interaction of a solute with a continuum. A direct utilizaion of $A B$ initio molecular potentials for the prevision of solvent effects. Journal of Chemical Physics, 55, 117-129.

Mikulski, C. M., Grossman, S., Lee, C. J., 2007. Hypoxanthine, xanthine and theobromine complexes with palladium(II) and platinum(IV) chlorides. Transition Metal Chemistry, 12, 21-25.
Mourik, T. V., Price, S. L., Clary, D. C., 1999. Ab Initio Calculations on Uracil-Water. Journal of Physical Chemistry A, 103, 1611-1618.

Oettl, K., Reibnegger, G., 1999. Pteridines as inhibitors of xanthine oxidase: structural requirements. Biochimica Biophysica Acta, 1430, 387.

Parr, R.G., Pearson, R.G., 1983. Absolute hardness: companion parameter to absolute electronegativity. Journal of American Chemical Society, 105, 75127516.

Parr, R.G., 1999. Electrophilicity Index. Journal of American Chemical Society, 121, 1922-1924.

Parthasarathi, R., Subramanian, V., Sathyamurthy, N., 2005. Hydrogen Bonding in Phenol, Water, and Phenol-Water Clusters. Journal of Physical Chemistry A, 109, 843-850.

Shahidha, R., Al-Saadi, A. A., Muthu, S., 2015. Vibrational spectroscopic studies, normal co-ordinate analysis, first order hyperpolarizability, HOMO-LUMO of midodrine by using density functional methods. Spectrochimica Acta Part A, 134, 127-142.

Tewari, B. B., Beaulieu-Houle, G., Larsen, A., KengneMomo, R., Auclair, K., Butler, I. S. 2012. An Overview of Molecular Spectroscopic Studies on Theobromine and Related Alkaloids. Applied Spectroscopy Review, 47, 163-179.

Ucun, F., Sağlam, A., Güçlü, V., 2007. Molecular structures and vibrational frequencies of xanthine and its methyl derivatives (caffeine and theobromine) by ab initio Hartree-Fock and density functional theory calculations. Spectrochimica Acta A, 67, 342-349

Wang, Y., Liu, Q., Qui, L., Wang, T., Yuan, T., Lin, J., Luo, S., 2015. Molecular structure, IR spectra, and chemical reactivity of cisplatin and transplatin: DFT studies, basis set effect and solvent effect. Spectrochimica Acta A, 150, 902-908.

Yurdakul, Ş. Bilkan, M., T., 2015. Spectroscopic and structural properties of 2, 2'-dipyridylamine and its palladium and platinum complexes. Optics and Spectroscopy, 119, 4, 603-619. 